
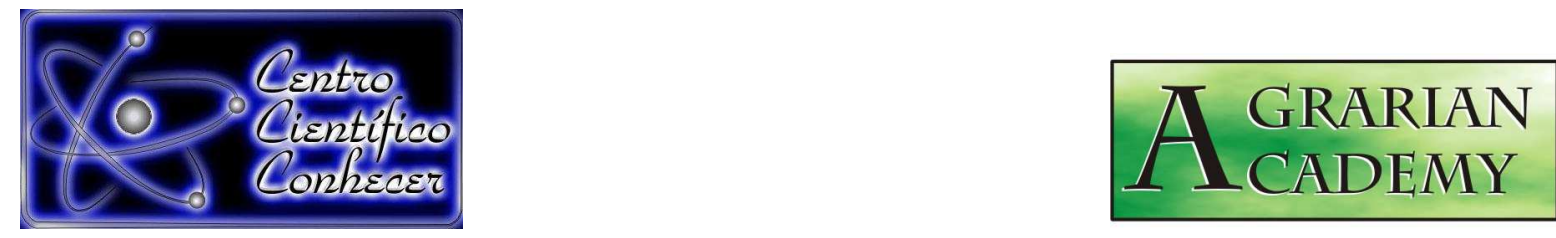

\title{
APLICAÇÃO DE DUAS FONTES DE ADUBAÇÃO NITROGENADA SUBMETIDA A DOSES CRESCENTES NA CULTURA DO RABANETE (Raphanus sativus L.) NA AMAZÔNIA OCIDENTAL
}

\author{
Jhonny Kelvin Dias Martins ${ }^{1}$; Silvana Ramlow Otto Teixeira da Luz ${ }^{1}$; Andressa \\ Graebin Ferreira ${ }^{1}$; Cleidson Alves da Silva ${ }^{2}$ \\ ${ }^{1}$ Graduando (a) do curso de Agronomia, Fundação Universidade Federal de \\ Rondônia - UNIR, (jhonny.jkdm@gmail.com) Rolim de Moura- Brasil \\ ${ }^{2}$ Graduado (a) em Agronomia, Fundação Universidade Federal de \\ Rondônia - UNIR, Rolim de Moura- RO, Brasil
}

Recebido em: 30/11/2017 - Aprovado em: 15/12/2017 - Publicado em: 31/12/2017

DOI: 10.18677/Agrarian Academy 2017b7

\begin{abstract}
RESUMO
O rabanete (Raphanus sativus L.) vem se destacando por ser um cultivo de ciclo rápido, além de ser uma boa alternativa de renda para o produtor rural, tem um excelente teor nutricional, ao longo dos anos vem crescendo a área de produção em Rondônia, mas no entanto falta muita informação sobre o manejo dessa cultura principalmente em termos de adubações. Diante disso objetivou-se avaliar duas fontes de adubação nitrogenada testando doses crescentes. O experimento foi instalado no Campus experimental do curso de Agronomia da Universidade Federal de Rondônia (UNIR) no município de Rolim de Moura. O delineamento experimental utilizado foi de blocos casualizados em parcelas subdivididas $2 \times 5$, com três repetições, a parcela principal era composta por duas fontes de adubação nitrogenada (Ureia $45 \% \mathrm{~N}$ e Nitrato de cálcio 15\% N) e as sub-parcelas representavam as cinco doses de adubação nitrogenada $\left(0 ; 25 ; 50 ; 100 ; 200 \mathrm{~kg} \mathrm{ha}^{-1}\right)$ foi utilizado a cultivar de rabanete Crimson gigante, a semeadura ocorreu no dia 15 de agosto de 2017. As variáveis analisadas foram, altura da planta, número de folhas, massa fresca da parte aérea e produtividade. As fontes de adubação não obtiveram efeito significativo, no entanto as doses crescentes em todas as variáveis analisadas teve um comportamento em que foi encontrado um modelo polinomial quadrático, destacando-se a dose máxima de $120 \mathrm{~kg} \mathrm{ha}^{-1}$ para a produtividade do rabanete.
\end{abstract}

PALAVRAS-CHAVE: Crimson gigante, nitrogênio, produção. 


\title{
APPLICATION OF TWO SOURCES OF NITROGEN FERTILIZATION SUBMITTED TO DOSES GROWING IN THE RABANET (Raphanus sativus L.) CULTURE IN THE WESTERN AMAZON
}

\begin{abstract}
The radish (Raphanus sativus L.) has been outstanding for being a fast cycle crop, besides being a good income alternative for the rural producer, has an excellent nutritional content, over the years has been growing the production area in Rondônia , but there is still a lot of information on the management of this crop, mainly in terms of fertilization. The objective of this study was to evaluate two sources of nitrogen fertilization by testing increasing doses. The experiment wasinstalled in the experimental Campus of the Agronomy course of the Federal University of Rondônia (UNIR) in the municipality of Rolim de Moura. The experimental design was a randomized block in $2 \times 5$ subdivided plots, with three replications. The main plot consisted of two sources of nitrogen fertilization (Urea $45 \% \mathrm{~N}$ and calcium Nitrate $15 \% \mathrm{~N})$ and the subplots represented the $\left(0 ; 25 ; 50 ; 100 ; 200 \mathrm{~kg} \mathrm{ha}^{-1}\right)$ was applied to the giant Crimson radish cultivar at sowing occurred on August 15, 2017. The variables analyzed were plant height, number of plants leaves, fresh shoot mass and productivity. The fertilizer sources did not obtain a significant effect, however, the increasing doses in all variables analyzed had a behavior where a quadratic polynomial model was found, with a maximum dose of $120 \mathrm{~kg} \mathrm{ha}^{-1}$ for radish productivity.
\end{abstract}

KEYWORDS: Crimson Giant, Production, Nitrogen

\section{INTRODUÇÃO}

O rabanete (Raphanus sativus L.) é originário da região mediterrânea (RODRIGUES et al., 2013), é uma cultura de ciclo relativamente curto e encontrou na região da Amazônia ocidental as condições edafoclimáticas ideais para um bom desempenho produtivo. Apesar de não representar muito em termos de área plantada e produção, é uma cultura de elevada rentabilidade e de rápido retorno econômico, devido ao ciclo curto (CARDOSO; HIRAKI, 2001).

O consumo ocorre principalmente na forma de saladas e conservas (SILVA et al., 2012). O valor nutritivo em grande parte ocorre em função da presença de vitaminas, especialmente o Potássio e Magnésio (EMBRAPA, 2014). De acordo com Filgueira (2013) essa cultura vem ganhando destaque entre os olericultores, principalmente por apresentar características atraentes, como ciclo curto e rusticidade, sendo a colheita realizada de 25 a 35 dias após a semeadura. Assim nem sempre é possível dispor de tempo e mão de obra suficiente para realizar adubação em cobertura em culturas de ciclo muito rápido.

O rabanete tem curto período de crescimento, durante o qual forma uma grande quantidade de massa no órgão de armazenamento, o que requer uma elevada quantidade de nutrientes, especialmente nitrogênio e potássio (OLIVEIRA et al., 2014). De acordo com Coutinho Neto et al. (2010) em função do período curto de tempo, problemas nutricionais dificilmente podem ser corrigidos dentro do ciclo, principalmente para o $\mathrm{N}$, um dos nutrientes normalmente requeridos em grandes quantidades pela cultura.

De acordo com Nascimento et al. (2017) o fornecimento adequado de nitrogênio é um dos principais fatores que afetam a qualidade e a produtividade das 
hortaliças, sendo que o manejo correto é necessário para obter sucesso com a cultura. Embora o nitrogênio seja um nutriente importante para as hortaliças, ainda pouco se conhece a respeito de quantidades a serem utilizadas na cultura do rabanete (QUADROS et al., 2010). Assim, objetivou-se avaliar o crescimento e produtividade de plantas de rabanete submetida a duas fontes de adubação nitrogenada em diferentes doses crescentes.

\section{MATERIAL E MÉTODOS}

O experimento foi instalado no Campus experimental do curso de Agronomia da Universidade Federal de Rondônia (UNIR), localizado no município de Rolim de Moura RO. O Campus experimental está localizado a $15 \mathrm{~km}$ da cidade, latitude 11ㄴㅇ'13" Sul longitude 6148'12" oeste, estando a 290 metros acima do nível do mar.

O clima é tropical quente e úmido com estações de seca bem definida (junho a setembro) com chuvas intensas nos meses de novembro a março. A precipitação média atual é de $2.250 \mathrm{~mm}$, umidade relativa do ar elevada, no período chuvoso, em torno de $85 \%$. As temperaturas médias mínimas são de $24^{\circ} \mathrm{C}$ e as máximas são de $32^{\circ} \mathrm{C}$. O solo foi classificado como Latossolo Vermelho-amarelo distrófico. Com as seguintes características químicas: $\mathrm{pH}$ em $\mathrm{H}_{2} \mathrm{O}$ 6,44; $\mathrm{M} . \mathrm{O}, 8,36 \mathrm{~g} \mathrm{dm}^{-3} ; \mathrm{P} 1,11 \mathrm{mg}$

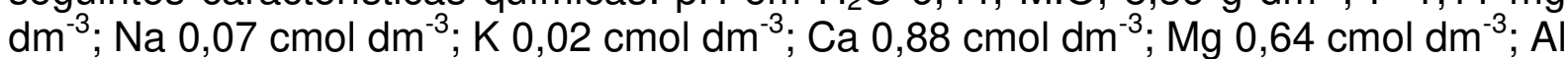
$0,00 \mathrm{cmol} \mathrm{dm}^{-3}$; $\mathrm{H}+\mathrm{Al} 3,63 \mathrm{cmol} \mathrm{dm}^{-3}$; Arg. 21,0\%; Areia 43,88\%.

O delineamento experimental utilizado foi de blocos casualizados em parcelas subdivididas $2 \times 4$, com três repetições. A parcela principal composta por duas fontes de adubação nitrogenada (Ureia e Nitrato de cálcio) e as sub-parcelas representavam as cinco doses de adubação nitrogenada $(0 ; 25 ; 50 ; 100 ; 200 \mathrm{~kg} \mathrm{ha}$ $\left.{ }^{1}\right)$.

O preparo do solo ocorreu de maneira convencional com uma gradagem, os canteiros foram levantados de forma manual, contendo um metro de largura e oito metros de comprimento e $30 \mathrm{~cm}$ de altura, foi adotado o espaçamento de $20 \times 0,8 \mathrm{~cm}$, cada sub parcela era constituída de $u m \mathrm{~m}^{2}$ e cada parcela principal quatro $\mathrm{m}^{2}$. $\mathrm{A}$ semeadura da cultivar de rabanete Crimson gigante ocorreu no dia 15 de agosto de 2017, adotando um espaçamento de $25 \mathrm{~cm}$ entre linhas e $8 \mathrm{~cm}$ por planta, foram semeadas diretamente nos canteiros, e o desbaste ocorreu três dias após a germinação, para fins das análises dos dados foram coletadas as quatro plantas centrais da área útil, descontando as bordas.

Realizou-se a adubação com $\mathrm{P}_{2} \mathrm{O}_{5}$ e $\mathrm{K}_{2} \mathrm{O}$, conforme 0 manual de recomendações de adubação e calagem de Minas Gerais (RIBEIRO et al., 1999). No decorrer do experimento foram realizados todos os tratos culturais necessários para o desenvolvimento das plantas, sendo: controle de pragas, doenças, plantas invasoras e manutenção da capacidade de campo para evitar o estresse hídrico durante o período do experimento, a colheita foi realizada aos 35 dias após a semeadura.

Os caracteres avaliados foram:

Altura da planta (ALT), foi mensurada com auxilio de uma fita métrica e o resultado obtido em centimetros.

Numero de folhas (№ FL) para a obtenção dos dados contados somente as folhas completamente desenvolvidas.

Massa fresca da parte aerea (MFA) coletada toda a parte aerea da planda, pesandoas com auxilio de uma balança de precisão. 
Produtividade (PROD) foram coletadas cinco plantas da parcela, estimulando a produtividade em $\mathrm{t} \mathrm{h}^{-1}$.

Os dados foram submetidos à análise de variância pelo teste $F(p \leq 0,05)$. Sendo os resultados significativos realizou-se a comparação de médias, utilizando o teste de Tukey ao nível de $5 \%$ de probabilidade. E, para variáveis quantitativas, ajustadas equações de regressão. As análises foram realizadas com o programa computacional Assistat 7.7 (SILVA; AZEVEDO, 2002).

\section{RESULTADOS E DISCUSSÃO}

Não houve efeito significativo para as fontes de adubação nitrogenada. Em relação às doses de nitrogênio, observou-se efeito significativo para todas as análises avaliadas $(p \leq 0,01)$ (Tabela 1$)$.

TABELA 1. Resumo da análise de variância para Altura da planta (ALT), Numero de folhas (№ FL), Massa fresca da parte aérea (MFA), Produtividade (PROD) submetidas a duas fontes de adubação Nitrogenada (Ureia e Nitrato de Cálcio) e diferentes doses de nitrogênio.

\begin{tabular}{|c|c|c|c|c|c|}
\hline \multirow{2}{*}{ Fontes de Variação } & \multirow[t]{2}{*}{$\mathrm{GL}$} & \multicolumn{4}{|c|}{ QM } \\
\hline & & ALT & № FL & MFA & PROD \\
\hline Fontes de $N(A)$ & 1 & $0.5531^{n s}$ & $3.0020^{\mathrm{ns}}$ & $0.0052^{\mathrm{ns}}$ & $1.8189^{\mathrm{ns}}$ \\
\hline Doses de N (B) & 4 & $16.9044^{--}$ & $22.7515^{--}$ & $5.286^{--}$ & $147.24^{--}$ \\
\hline Interação A x B & 4 & $2.0752^{\mathrm{ns}}$ & $0.6735^{\mathrm{ns}}$ & $0.114^{\mathrm{ns}}$ & $4.66^{\mathrm{ns}}$ \\
\hline Resíduo & & 6.53147 & 0.11228 & 1.0095 & 0.907 \\
\hline CV\% & & 11.69 & 7.17 & 8.81 & 8.68 \\
\hline Regressão Linear & & $42.853^{\mathrm{ns}}$ & $54.377^{\text {ns }}$ & $13.585^{\mathrm{ns}}$ & $146.80^{\text {ns }}$ \\
\hline Regressão Quadrática & & $17.238^{* *}$ & $32.991^{* *}$ & $6.263^{* *}$ & $367.76^{\star *}$ \\
\hline Regressão Cúbica & & $7.2846^{\mathrm{ns}}$ & $0.4189^{n s}$ & $1.295^{\mathrm{ns}}$ & $57.53^{\mathrm{ns}}$ \\
\hline
\end{tabular}

As doses de nitrogênio influenciaram significamente sendo o modelo quadrático o que melhor se ajustou aos valores de altura da planta, massa fresca da parte aérea, número de folhas (Figura 1). Segundo Cardoso; Hirakl (2001) em seu trabalho observaram aumento na altura da planta e massa fresca da raiz do rabanete com doses crescentes de adubação nitrogenada (0;50;100 e $\left.200 \mathrm{~kg} \mathrm{ha}^{-1}\right)$. Resultados diferentes foram observados por Pedó et al. (2014) avaliando o crescimento de rabanete em função da adubação $\mathrm{N}$ notaram que a dose de $15 \mathrm{~kg}$ $\mathrm{ha}^{-1}$ proporcionou melhores características de crescimento às plantas.

A dose que expressou os melhores resultados foi a dose de $100 \mathrm{~kg} \mathrm{ha}^{-1}$ obtendo altura de planta superior a $20 \mathrm{~cm}$ (Figura 1A). $O$ nitrogênio é um macronutriente muito exigido pelas culturas de maneira geral, por atuar no desenvolvimento vegetativo das plantas, o que explica o incremento na altura promovido pela aplicação de N (FORNASIERI FILHO, 2007).

Em relação a massa fresca da parte aérea foi obtido um modelo polinomial quadrático e o ponto máximo de produção de massa ocorreu quando adicionado 105 $\mathrm{kg} \mathrm{ha}^{-1}$ de $\mathrm{N}$, a massa fresca da parte aérea em resposta a adubação nitrogenada foi 
de $16 \mathrm{~g}$ (Figura 1B). Para Filgueira (2013), o incremento da massa da parte aérea é importante, pois, em hortaliças tuberosas constata-se correlação direta e positiva entre o peso da parte aérea e a produtividade.

Conforme Malavolta et al. (1997) o N na planta possui função estrutural, sendo constituinte de aminoácidos, proteínas, bases nitrogenadas, muitas enzimas e materiais de transferência de energia, como a clorofila, ADP e ATP, tendo também papel nos processos de absorção iônica, fotossíntese, respiração, multiplicação e diferenciação celular. Conseqüentemente uma planta nutrida adequadamente com nitrogênio, tende a aumentar a massa da parte aérea. Caetano et al. (2015) não obtiveram efeito significativo para massa fresca da parte aérea do rabanete com o incremento crescente de doses de nitrogênio. Em relação ao número de folhas ocorreu aumento do incremento até a dose de $100 \mathrm{~kg} \mathrm{ha}^{-1}$, a partir dessa dose houve decréscimo no número de folha (Figura 1C).

De acordo com Nascimento et al., (2017) o fornecimento adequado de nitrogênio é um dos principais fatores que afetam a qualidade e a produtividade das hortaliças, sendo que o manejo correto é necessário para obter sucesso com a cultura. Altas doses de fertilizantes podem causar toxidez a planta ou reduzir a absorção de outros nutrientes afetando diretamente o desenvolvimento.
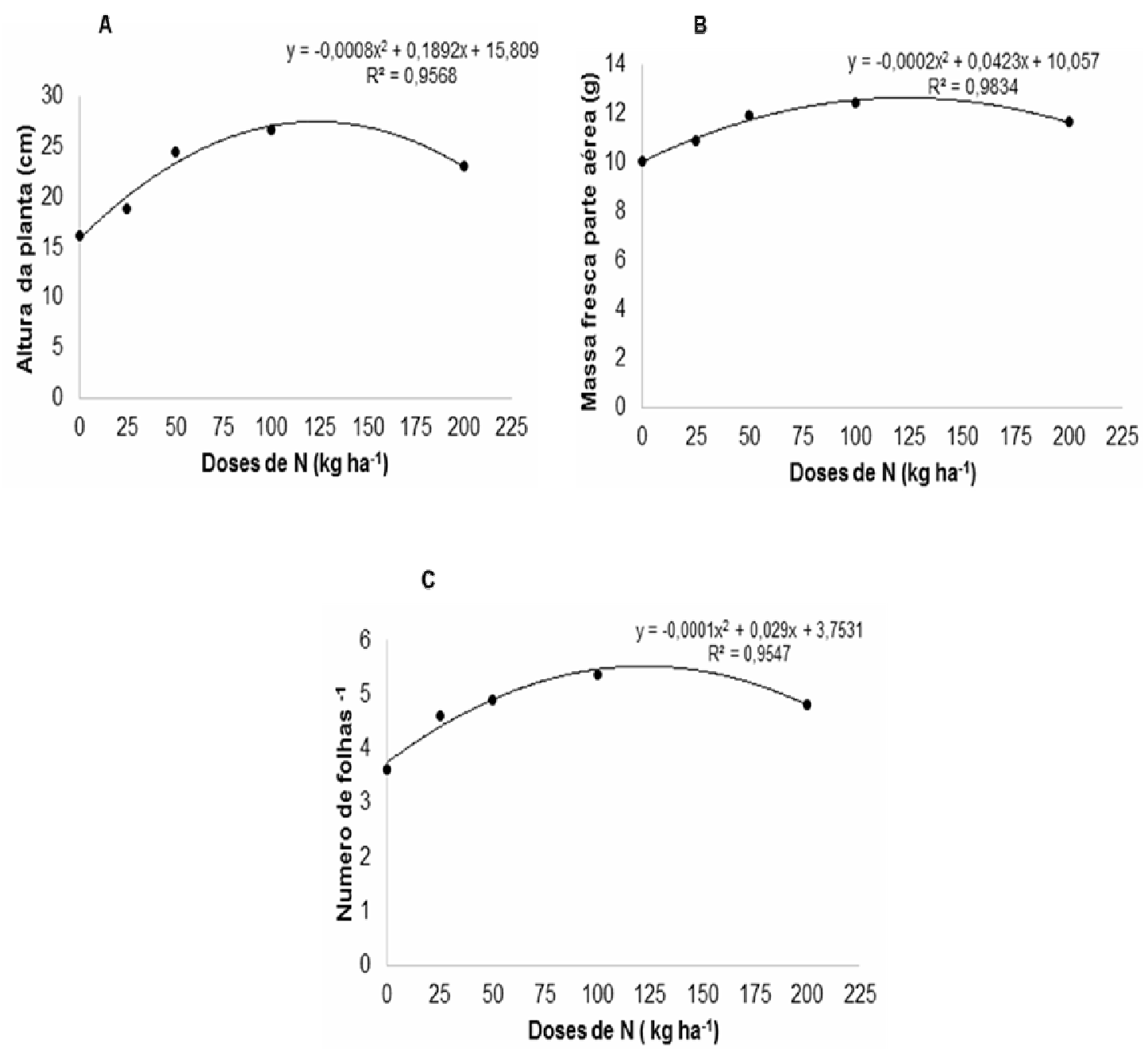

FIGURA 1. Altura da planta (A), Massa fresca da parte aérea (B), Números de folhas $(C)$, em função da aplicação de doses de nitrogênio. 
O modelo quadrático foi o que melhor ajustou-se aos valores de Produtividade do rabanete em função da adubação com diferentes doses de nitrogênio (Figura 2). De acordo com este modelo de regressão, foi estimado que o ponto máximo de produtividade ocorreu quando adicionado $120 \mathrm{~kg} \mathrm{ha}^{-1}$ de $\mathrm{N}$ obtendo um incremento de 16,5 tha ${ }^{-1}$, ao aplicar doses superiores ocorre um decréscimo na produtividade.

Resultados semelhantes com a mesma cultivar de rabanete (Crimson Gigante) foram encontrados por Oliveira et al. (2014), que verificaram que a aplicação de $120 \mathrm{~kg}$ de $\mathrm{N}$ ha ${ }^{-1}$ proporcionou $\mathrm{o}$ maior diâmetro da raiz consequentemente afetando a produtividade.

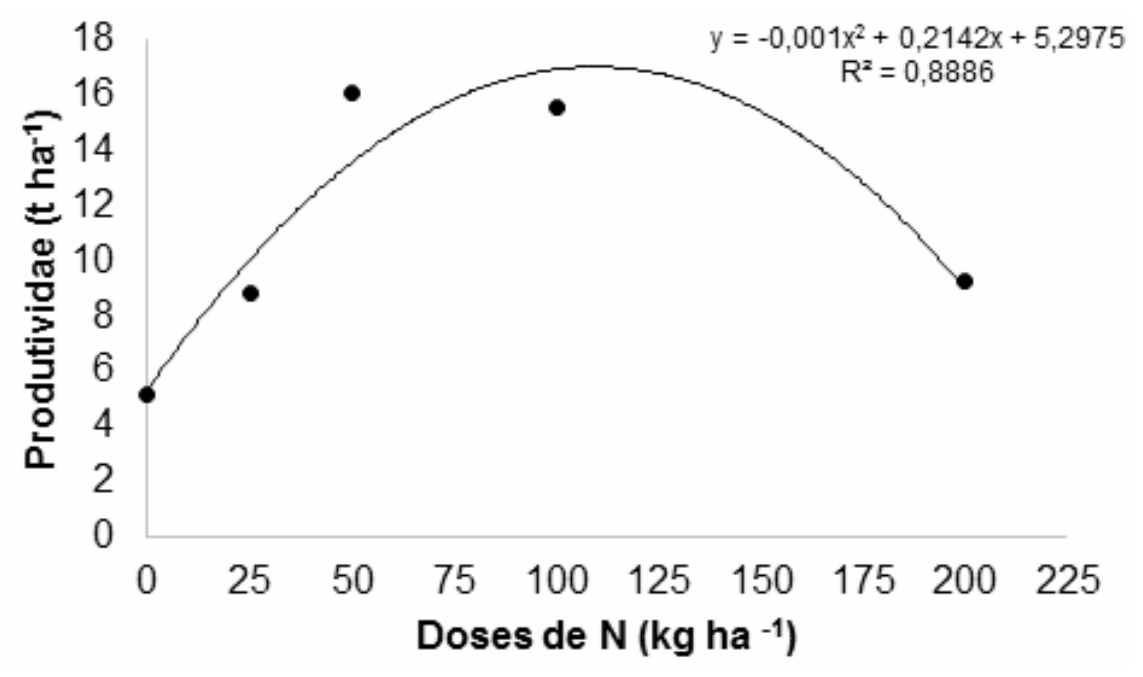

FIGURA 2: Produtividade do rabanete em função da aplicação de doses crescente de nitrogênio.

\section{CONCLUSÃO}

As fontes de adubação nitrogenada não apresentaram efeito significativo para as variáveis. A dose de nitrogênio que apresentou os melhores resultados para a região da Amazônia ocidental foi a dose de $120 \mathrm{~kg} \mathrm{ha}^{-1}$.

\section{REFERÊNCIAS}

CARDOSO, A. I. I.; HIRAKI, H. Avaliação de doses e épocas de aplicação de nitrato de cálcio em cobertura na cultura do rabanete. Horticultura Brasileira, Brasília, v.19, n.3, p. 196-199, 2001.

CAETANO, A. O.; DINIZ, R. L. C.; BENETT, C. G. S.; SALOMÃO, L. C. Efeito de fontes e doses de nitrogênio na cultura do rabanete. Revista de Agricultura Neotropical, Cassilândia-MS, v. 2, n. 4, p. 55-59, out./dez. 2015

COUTINHO NETO, A. M.; ORIOLI JÚNIOR, V.; CARDOSO, S. S.; COUTINHO, E. L. M. Produção de matéria seca e estado nutricional do rabanete em função da 
adubação nitrogenada e potássica. Nucleus, Ituverava-SP, v.7, n.2, p. 105-114, 2010. <http://dx.doi.org/10.3738/nucleus.v7i2.349> DOI: 10.3738/1982.2278-349

EMBRAPA. Hortaliças em números: Situação da produção de hortaliças no Brasil, 2014. em http://www.cnph.embrapa.br/paginas/hortalicas_em_numeros/hortalicas_em_ numeros.htm.

FILGUEIRA, F. A. R. Novo manual de olericultura: Agrotecnologia moderna na produção e comercialização de hortaliças. Viçosa: UFV, ed.3, p.421, 2013.

FORNASIERI FILHO, D. Manual da cultura do milho. Jaboticabal: Funep, 576 p. 2007.

NASCIMENTO, M. V.; SILVA JUNIOR, R. L.; FERNANDES, L. R.; XAVIER, R. C.;BENETT, K. S. S.; SELEGUINI, A.; BENETT, C. G. S. Manejo da adubação nitrogenada nas culturas de alface, repolho e salsa. Revista de Agricultura Neotropical, Cassilândia-MS, v. 4, n. 1, p. 65-71, jan./mar. 2017.

MALAVOLTA, E.; VITTI, G. C.; OLIVEIRA, S. A. Avaliação do estado nutricional das plantas: princípios e aplicações. 2. ed. Piracicaba: POTAFOS, 319p. 1997.

OLIVEIRA, G. Q.; BISCARO, G. A.; MOTOMIYA, A. V. A.; JESUS, M. P. E FILHO, P. S. V. Aspectos produtivos do rabanete em função da adubação nitrogenada com e sem hidrogel. Journal of Agronomic Sciences, vol. 3, n. 1, p. 89-100, 2014. $<$ http://www.dca.uem.br/V3N1/09-Gabriel.pdf>

PEDÓ, T.; AUMONDE, T. Z.; MARTINAZZO, E. G.; VILLELA, F. A.; LOPES, N. F.; $\mathrm{MAUCH}, \mathrm{C}$. R. Análise de crescimento de plantas de rabanete submetidas a doses de adubação nitrogenada. Bioscience Journal, Uberlândia-MG, v. 30, n. 1, p. 1-7, 2014.

QUADROS, B. R. de; SILVA, E. S.; BORGES, L. S.; MOREIRA, C. A.; MORO, A. L.; VILLAS BÔAS, R. L. Doses de nitrogênio na produção de rabanete fertirrigado e determinação de clorofila por medidor portátil nas folhas. Irriga. Botucatu, v.15, p.353-360, out-dez 2010.

RODRIGUES, R. R.; PIZETTA, S. C. P.; TEIXEIRA, A. G.; REIS, E. F.; HOTT, M. O. Produção de rabanete em diferentes disponibilidades de água no solo. Enciclopédia Biosfera, v.9, n.17, p. 2121-2130. 2013.

RIBEIRO, A. C.; GUIMARÃES, P. T. G.; ALVAREZ V., V. H. (Ed.). Recomendação para o uso de corretivos e fertilizantes em Minas Gerais: $5^{\underline{a}}$ aproximação. Viçosa 1999.

SILVA, C. R. M.; SILVEIRA, M. H. D. Fertirrigação da cultura do rabanete com Diferentes dosagens de nitrogênio. Enciclopédia Biosfera, v. 8, n.15, p. 947-953, 2012. 
SILVA F. A. S. \& AZEVEDO C. A. V. Versão do programa computacional Assistat para o sistema operacional Windows. Revista Brasileira de Produtos Agroindustriais, v.4, 71-78, 2002. <http://dx.doi.org/10.15871/15178595/rbpa.v4n1p71-78> DOI: 10.15871/1517-8595 